\title{
INVESTIGATING THE EFFECT OF DIFFERENT GRADES AND CONCENTRATIONS OF PH-SENSITIVE POLYMER ON PREPARATION AND CHARACTERIZATION OF LIDOCAINE HYDROCHLORIDE AS IN SITU GEL BUCCAL SPRAY
}

\author{
HALAH TALAL SULAIMAN*, SABA ABDULHADI JABIR, KHALID KADHEM AL-KINANI
}

Department of Pharmaceutics, College of Pharmacy, University of Baghdad, Baghdad, Iraq. Email: halahtalal46914@gmail.com Received: 30 July 2018, Revised and Accepted: 04 September 2018

\section{ABSTRACT}

Objective: The present study was aimed to develop a pH-triggered in situ gel for local release of lidocaine hydrochloride (lidocaine HCL) in the buccal cavity to improve the anesthetic effect of this amino amide drug which has very high water solubility. The formulations were introduced to the oral cavity as a spray to improve compliance and for easier administration.

Methods: In this work, two grades of carbopol (934 and 940)-based in situ gel spray were designed. The formulations containing lidocaine HCl 5\% were prepared by mixing different concentrations of carbopol with xanthan gum. Eight formulations were investigated and evaluated for gelation capacity, spray angle, volume of solution delivered per each actuation, rheological properties, and release kinetic model. Similarity factor $\left(f_{2}\right)$ was used for the comparison of dissolution profiles.

Results: The prepared formulations undergo gelation after it had been actuated to the buccal cavity as a spray solution. The results showed that, as the concentration of polymer was increased, the release of drug decreased and the viscosity increased for both grades. The spray angle and volume of solution delivered per each actuation varied according to the composition of each formulation. The in situ gel containing $0.3 \%$ carbopol 934 and $0.2 \%$ xanthan gum regarded as a better candidate which had a good gelation and release property compared to other formulations. Drug release from optimized in situ gel spray followed Korsmeyer-Peppas model and was mediated by Fickian diffusion mechanism.

Conclusion: Lidocaine HCl-loaded pH-sensitive in situ gel was successfully developed using carbopol 934 as polymer to be applied to the buccal cavity as spray solution for more effective anesthetic effect and painless treatment.

Keywords: Lidocaine Hydrochloride, Carbopol, In situ gel.

(C) 2018 The Authors. Published by Innovare Academic Sciences Pvt Ltd. This is an open access article under the CC BY license (http://creativecommons. org/licenses/by/4. 0/) DOI: http://dx.doi.org/10.22159/ajpcr.2018.v11i11.28492

\section{INTRODUCTION}

The development of in situ gel systems has received considerable attention over the past few years. This interest has been sparked by the advantages shown by in situ-forming polymeric delivery systems such as ease of administration and reduced frequency of application, as well as improved patient compliance and comfort [1]

In situ gelling systems are liquid at room temperature but undergo gelation when they come into contact with body fluids or on change in $\mathrm{pH}$. In contrast to hard gels, they can be easily applied in liquid form to the site of drug absorption. At the site of drug absorption, they swell to form a hard and bioadhesive gel that is capable of prolonging the residence time of the active substance.

Both natural and synthetic polymers can be used for the production of in situ gels, whose gelation can be triggered due to one or combination of different stimuli such as $\mathrm{pH}$ change, temperature modulation, and/or ionic crosslinking. It can be administered through different routes such as oral, ocular, rectal, vaginal, injectable, and intraperitoneal routes [2-4].

A promising in situ gel system is a pH-sensitive in situ forming gel which can undergo gelation based on change in $\mathrm{pH}$ as the sole physiological stimulus. All the $\mathrm{pH}$-sensitive polymers contain pendant acidic or basic groups that can either accept or release protons in response to changes in environmental pH. Polymers with a large number of ionizable groups are known as polyelectrolytes. Swelling of these polymers increases as the external $\mathrm{pH}$ increases in the case of weakly acidic (anionic) group-rich polymer but decreases if the polymer contains weakly basic (cationic) groups. Most of anionic pH-sensitive polymers are based on polyacrylic acid (Carbopol@, carbomer) or its derivatives and are present as solution at acidic $\mathrm{pH}$ but converted to viscous gel on raise in the $\mathrm{pH}[5-7]$.

The buccal drug delivery system has many advantages over the conventional and systemic formulation majority. It helps in enhancing the bioavailability through bypassing the first-pass metabolism effect, the mucosal surface better absorption, and prolonged resident time. Among the various transmucosal sites available, mucosa of the buccal cavity was found to be the most convenient and easily approachable site for the delivery of the therapeutic agent for both local and systemic deliveries [8].

The design of oral sprays is usually a logical choice to improve patient's compliance. In addition to that, the release of the medicament can be rapid in the form of micro-sized droplets in the oral cavity to be absorbed by buccal mucosa. This can result in a direct and rapid dispersion of a solution of the active agent over a large portion of the oral mucosa for better absorption of the active agent through the mucosal barrier [9].

Topical anesthetics are useful medicines during dental treatment, as they reduce dental phobia, especially in children, by mitigating discomfort and pain [10].

The mean of the administration of local anesthetic, namely injection, can cause fear and anxiety during dental treatment. The pain and discomfort resulting from injection can be minimized by a variety of techniques. These include appropriate behavior management techniques, altering the $\mathrm{pH}$ and temperature of the anesthetic solution and injecting the solution at a reduced rate [11]. 
On the other hand, topical anesthetic gels are easy to apply, but they possess some drawbacks such as a tendency to spread to other areas and lower retention in plaque area. Therefore, these gels can cause numbness of lips, tongue, and cheeks and have a bigger chance of accidental swallowing of the gel. To improve the residence time, in situ gels show promising effect [12]

Lidocaine is the prototype amino amide, local anesthetics and has been in use for many years. In dentistry, it is a drug of choice to temporarily anesthetize the tiny nerve endings located on the surfaces of the oral mucosa. As a local anesthetic, lidocaine is characterized by a rapid onset of action and intermediate duration of efficacy, making it suitable for infiltration and nerve block anesthesia. Lidocaine stabilizes the neuronal membrane by inhibiting the ionic fluxes required for the initiation and conduction of impulses, thereby effecting local anesthetic action [13]

There are several pharmaceutical dosage forms of lidocaine HCL available in the market such as solution for injection or infusion, nasal spray, oral gel, and transdermal patches $[14,15]$.

In previous literatures, no attempt has been taken to formulate lidocaine HCL as buccal in situ gel spray. In the present study, a pH-triggered in situ gel as a buccal drug delivery system was developed. The gel system is to be made from polymers that exhibit phase transition due to physicochemical change in the environment. This gel system can be conveniently sprayed as a solution into the buccal mucous, and on contact with the saliva, the system changes its conformation to form a gel. This delivery system can provide the ease of administration to the patient similar to spray solution and can also provide a long retention time for the longer duration of action because of the gel formation.

\section{MATERIALS AND METHODS}

\section{Materials}

Lidocaine HCL, xanthan gum, and propylparaben were supplied by Samarra Drug Industry as a gift. Carbopol 934 and 940 were purchased from HiMedia Laboratories Pvt, Ltd., Mumbai, India. All other chemicals and solvents were of analytical reagent grade, and deionized water was used in this study.

\section{Method}

\section{Selection of polymer}

In this work, two grades of carbopol were used (carbopol 934 and carbopol 940) as in situ gelling polymers. It was found that mixing carbopol (either grade) with Lidocaine HCL leads to the formation of a precipitate. Therefore, it was decided to add other polymers to prevent the formation of the precipitate and helps improve the stability of the preparations.

The investigated polymers were each of hydroxyl propyl methyl cellulose, xanthan gum, sodium carboxymethyl cellulose, sodium alginate, and guar gum. Each of these polymers was tested separately in combination with carbopol and lidocaine $\mathrm{HCl}$ solution to achieve the best polymer combination for the formulation of the intended in situ gel.

\section{Preparation of pH-induced in situ gel}

Eight formulations were designed as shown in Table 1 using various concentrations of carbopol 934 and $940(0.1,0.3,0.5$, and $0.7 \% \mathrm{w} / \mathrm{v})$ in combination with $0.2 \%(\mathrm{w} / \mathrm{v})$ xanthan gum.

Carbopol and xanthan gum were dispersed in a beaker containing purified water and kept refrigerated at $4^{\circ} \mathrm{C}$ overnight to allow hydration. On the other hand, lidocaine $\mathrm{HCl}$ was dissolved in phosphate buffer $\mathrm{pH}$ 6.8. Propylparaben was added to the resulting drug solution. The drug solution was then added to polymer solution with constant stirring using electrical stirrer until a uniform solution was obtained. The volume of the final solution was brought up to $100 \mathrm{ml}$ using deionized water [16].

\section{Evaluation parameter}

\section{Visual appearance and clarity}

Visual appearance and clarity of the prepared solution were checked for the presence of any particulate matter using fluorescent light against a white and black background.

\section{$\mathrm{pH}$ of the formulation}

The $\mathrm{pH}$ of the developed formulations was evaluated using a digital $\mathrm{pH}$ meter. The $\mathrm{pH}$ probe was immersed in the formulation for $5 \mathrm{~min}$, and then, the readings were recorded.

\section{Content uniformity}

The drug content of the prepared in situ gel was determined by placing $1 \mathrm{ml}$ of formulation liquid in $100 \mathrm{ml}$ volumetric flask. The volume was made up to $100 \mathrm{ml}$ by adding phosphate buffer $\mathrm{pH} 6.8$ to the flask. Subsequently, a volume of $4 \mathrm{ml}$ of the diluted solution was taken out into a $10 \mathrm{ml}$ volumetric flask and the volume was adjusted with $\mathrm{pH} 6.8$ phosphate buffer [17].

Absorbance was measured using double-beam ultraviolet (UV) spectrophotometer at $272 \mathrm{~nm}$ [18]. The amount of drug present was calculated using calibration curve.

\section{Gelling capacity (sol-to-gel transition/in vitro)}

All prepared formulations were evaluated for gelling capacity to identify the composition suitable for use as in situ gelling system. The gelling capacity test was implemented by placing a drop of each formula in a $10-\mathrm{ml}$ beaker containing $5-\mathrm{ml}$ phosphate buffer and equilibrated at $37^{\circ} \mathrm{C}$. Visual assessment of the gel as it forms time for gelation as well as time taken for the gel formed to dissolve was monitored during this test [19].

\section{Syringeability}

All prepared formulations were transferred into an identical 5-ml syringe placed with 20 -gauge needle to a constant volume $(1 \mathrm{ml})$. The solutions which were easily passed from syringe were termed as pass, while difficult to pass solutions were termed as fail [20]

\section{Spray angle}

The in situ gel sprays were actuated in horizontal direction onto a white paper mounted at a distance of $1 \mathrm{~cm}$ from the nozzle. The radius of the circle, formed on the paper, was recorded for minimum and maximum diameters. Spray angle $(\theta)$ was calculated using equation 1 [21].

$(\theta)=\tan ^{-1}\left(\frac{1}{r}\right)$

Where $\theta=$ spray angle in degree, l=the distance of paper from the nozzle, and $r=$ average radius of circle.

\section{Volume of solution delivered per each actuation}

To determine the volume of prepared gel delivered per each actuation, the following equation was used:

$$
\mathrm{A}_{\mathrm{L}}=\left(\frac{w t-w o}{D a}\right)
$$

Where $A_{L}$ is the volume of solution delivered per each actuation, $\mathrm{W}_{\mathrm{t}}$ is weight of formulation after actuation,

$\mathrm{W}_{0}$ is initial weight of formulation before actuation, and Da is the density of the formulation

\section{Rheological studies}

Rheological properties of the prepared in situ gelling systems under different shear rates $(6,12,20,30$, and $60 \mathrm{rpm})$ were determined at nonphysiological $\left(\mathrm{pH} 4.5-5.8\right.$ and $\left.25^{\circ} \mathrm{C}\right)$ and physiological $\left(\mathrm{pH} 6.8\right.$ and $\left.37^{\circ} \mathrm{C}\right)$ conditions, respectively, using digital viscometer with spindle number 3 . The viscosity of the samples was recorded before and after gelation. 
Table 1: Formulation composition of lidocaine $\mathrm{HCl}$ buccal in situ gel spray (expressed as $\% \mathrm{w} / \mathrm{v}$ )

\begin{tabular}{|c|c|c|c|c|c|c|}
\hline $\begin{array}{l}\text { Formulation } \\
\text { code }\end{array}$ & $\begin{array}{l}\text { Lidocaine } \\
\mathrm{HCl}\end{array}$ & $\begin{array}{l}\text { Carbopol } \\
934\end{array}$ & $\begin{array}{l}\text { Carbopol } \\
940\end{array}$ & $\begin{array}{l}\text { Xanthan } \\
\text { gum }\end{array}$ & Propylparaben & Deionizedwater q. $s$ \\
\hline F1 & 5 & 0.1 & - & 0.2 & 0.02 & 100 \\
\hline $\mathrm{F} 2$ & 5 & 0.3 & - & 0.2 & 0.02 & 100 \\
\hline F3 & 5 & 0.5 & - & 0.2 & 0.02 & 100 \\
\hline F4 & 5 & 0.7 & - & 0.2 & 0.02 & 100 \\
\hline F5 & 5 & - & 0.1 & 0.2 & 0.02 & 100 \\
\hline F6 & 5 & - & 0.3 & 0.2 & 0.02 & 100 \\
\hline F8 & 5 & - & 0.7 & 0.2 & 0.02 & 100 \\
\hline
\end{tabular}

\section{In vitro release study}

The in vitro release study of lidocaine $\mathrm{HCl}$ was carried out using a modified dissolution apparatus Type II (paddle type). $1 \mathrm{ml}$ of each formulation was placed in a dialysis membrane $(0.08 \mu \mathrm{m}$ pore size $)$ which was previously soaked in phosphate buffer $\mathrm{pH}$ 6.8. The dialysis membrane is tied to the paddle shaft and immersed in $150 \mathrm{ml}$ phosphate buffer $\mathrm{pH} 6.8$ as a dissolution media rotated at $50 \mathrm{rpm}$ and maintained at $37 \pm 1^{\circ} \mathrm{C}[22]$.

Samples of $5 \mathrm{ml}$ were withdrawn at specific time interval and replaced with equal volume of fresh media. The samples were analyzed for drug concentration using UV visible spectrophotometer at $272 \mathrm{~nm}$.

\section{Analysis of release mechanism}

The release kinetics of lidocaine $\mathrm{HCl}$ from in situ gel formulation was evaluated considering four different models including zero order, first order, Higuchi model, and Korsmeyer-Peppas model using a Microsoft Excel plug-in program DD Solver [23].

\section{Dissolution profile comparison}

The similarities between two in vitro dissolution profiles were assessed by pair-wise independent model procedures named as similarity factor $\left(f_{2}\right)$. For similar release profiles, the similarity factor should be in the range of 50-100 (closer to 100) [24].

The similarity factor is a logarithmic reciprocal square root transformation of the sum of squared error and is a measurement of the similarity in the percentage of the dissolution between two curves:

$f_{2}=50 \log \left\{\left[1+\left(\frac{1}{n} \sum_{t=1}^{n}\left(R_{t}-T_{t}\right)\right)^{2}\right]^{-0.5} * 100\right\}$

Where $n$ is the sampling number, and $R t$ and $T t$ are the percentage of dissolved reference and test product at each time point $t$, respectively [25].

\section{Statistical analysis}

All experiments were run in triplicates. The obtained results were expressed as mean \pm standard deviation (SD). Analysis of variance test was used to determine the significance. The results were considered statistically significant at $\mathrm{p}<0.05$

\section{RESULTS AND DISCUSSION}

\section{Selection of polymer combination}

First, formulation containing carbopol alone was prepared. As observed during practical work that carbopol solution with lower concentration has low viscosity whereas at higher concentration, the viscosity was very high. However, the concentration of carbopol required to form stiff gel results in highly acidic solutions, which are not easily neutralized by the buffering action of the saliva.

Another problem was encountered that carbopol was precipitated on the addition of drug solution and this finding was also observed by Patil et al. when norfloxacin solution was added to carbopol solution [26]. It was stated previously that carbopol gel viscosity is dependent on the presence of electrolytes and the $\mathrm{pH}$, and generally, a maximum of $3 \%$ electrolytes can be added before a rubbery mass forms [27]. Therefore, to decrease the concentration of carbopol without compromising gelling capacity and rheological properties and improving the stability of the prepared gel, it was decided to use a viscosity increasing agent.

Hydroxypropyl methylcellulose, xanthan gum, sodium carboxy methylcellulose, sodium alginate, and guar gum were tested separately with carbopol and drug solution. It was found that xanthan gum formed the most stable dispersion with carbopol and drug solution without precipitation which can be explained by synergistic interaction takes place between xanthan gum and hydrocolloid, especially in the presence of salt, which is necessary for optimum functionality and stability of xanthan gum [28]

\section{Preparation of in situ gel}

Carbopol solutions of $0.1,0.3,0.5$, and $0.7 \%(\mathrm{w} / \mathrm{v})$ retained liquid state (free flow) at $\mathrm{pH}$ range $(4-5.8)$ and at $25^{\circ} \mathrm{C}$ and gelled on exposure to physiological conditions $\left(\mathrm{pH} 6.8\right.$ at $\left.37^{\circ} \mathrm{C}\right)$. Different concentrations of xanthan gum were tested $0.1 \%-0.4 \%(\mathrm{w} / \mathrm{v})$ to optimize the concentration suitable for in situ gel formulation. The optimum concentration of xanthan gum selected was $0.2 \%(\mathrm{w} / \mathrm{v})$. Xanthan gum concentration above $0.2 \%(\mathrm{w} / \mathrm{v})$ forms gel at formulation condition, so it can no longer be used.

\section{Evaluation parameter}

\section{Visual appearance and $\mathrm{pH}$}

All the prepared in situ gelling systems were evaluated for visual appearance, clarity, and $\mathrm{pH}$ as shown in Table 2. It was observed that, as carbopol concentration increases, the $\mathrm{pH}$ of the formulation becomes acidic due to the acidic nature of the polymer. The solution becomes translucent at $\mathrm{pH} \mathrm{4,} \mathrm{while} \mathrm{at} \mathrm{pH} \mathrm{5}$, it was clear. These findings were also observed in the preparation of $\mathrm{pH}$-induced in situ gelling system of lomefloxacin $\mathrm{HCl}$ [29].

\section{Content uniformity}

The drug content of the buccal formulations of lidocaine $\mathrm{HCl}$ in situ gel was found to be satisfactory ranging between $98.20 \% \pm 0.04$ and $99.10 \% \pm 0.03$, indicating uniform distribution of the drug throughout the formula.

\section{Gelling capacity (sol-to-gel transition/in vitro)}

From the physical appearance, it seems that formulation containing $0.1 \%-0.3 \%(\mathrm{w} / \mathrm{v})$ carbopol had free-flowing properties at nonphysiological pHs. On the other hand, for carbopol concentration equal to $0.3 \%(\mathrm{w} / \mathrm{v}$ ) (F2 and F6), a harder gel having higher gelation capacity was formed at physiological $\mathrm{pH}$ compared to $0.1 \%(\mathrm{w} / \mathrm{v})$ carbopol containing formulations (F1 and F5). Most of the formulations have shown an instantaneous gelation ( $<20 \mathrm{~s}$ ). Among the others (F4 and F8), the time required for complete gelation was $2-4 \mathrm{~min}$.

As the concentration of carbopol was increased ( 0.5 and $0.7 \% \mathrm{w} / \mathrm{v})$, the solution became more acidic and it cannot be neutralized by buffering 
action of salivary $\mathrm{pH}$, and thin gel was formed at physiological $\mathrm{pH}$ (Table 2).

Similar results were obtained by Nandgude et al. who studied the formulation of $\mathrm{pH}$-induced in situ nasal gel of salbutamol sulfate in that, as carbopol concentration was increased, the solution cannot be neutralized by nasal $\mathrm{pH}$ [30].

\section{Syringeability}

Syringeability of the formulations was determined as per material and concentration. Syringeability of all the formulations is shown in Table 3.

All the formulations were passed freely through the used syringe needle.

\section{Spray angle}

The results of spray angle are shown in Table 3. The spray angle was found to be significantly increased $(\mathrm{p}<0.05)$ in the range of $25.7^{\circ} \pm 0.3-$ $42^{\circ} \pm 0.1$ as the volume per each actuation increased and the viscosity decreased for either polymer grade. The same results of spray angle were obtained for oral cavity sprays containing herbal extracts [31]

\section{Volume per each actuation}

The average amount of the product delivered from spray devices was $0.11 \pm 0.011-0.15 \pm 0.023 \mathrm{ml}$, and the volume deviation could be attributed to formulation compositions and concentration.

\section{Rheological study}

Viscosity of formulations was measured as the change of shear rate under non-physiological and physiological conditions to investigate the rheology of these formulations. Figs. 1 and 2 show the rheological profile of the formulations at physiological and non-physiological $\mathrm{pH}$, respectively.

To apply easily at the affected site, the formulation must possess optimum viscosity. Furthermore, the formulation should undergo rapid sol-to-gel transition on contact with the affected site. It was found that,

Table 2: pH values and physical appearance of the prepared in situ gels

\begin{tabular}{lll}
\hline Formulation code & $\mathbf{p H}$ & Physical appearance \\
\hline F1 & $5.8 \pm 0.03$ & Thin transparent liquid \\
F2 & $5.07 \pm 0.02$ & Thin transparent liquid \\
F3 & $4.8 \pm 0.01$ & Translucent dispersion \\
F4 & $4.05 \pm 0.01$ & Opaque dispersion \\
F5 & $5.8 \pm 0.03$ & Thin transparent liquid \\
F6 & $5.2 \pm 0.02$ & Transparent dispersion \\
F7 & $4.7 \pm 0.02$ & Translucent liquid dispersion \\
F8 & $4.5 \pm 0.02$ & Translucent dispersion \\
\hline
\end{tabular}

All the values are in mean $\pm S D,(n=3)$. SD: Standard deviation

Table 3: Volume per each actuation, spray angle, and syringeability of the prepared in situ gels

\begin{tabular}{lllll}
\hline $\begin{array}{l}\text { Formulation } \\
\text { code }\end{array}$ & $\begin{array}{l}\text { Volume/each } \\
\text { actuation }(\mathrm{ml})\end{array}$ & $\begin{array}{l}\text { Spray } \\
\text { angle }\end{array}$ & Syringeability & $\begin{array}{l}\text { Gelation } \\
\text { capacity** }\end{array}$ \\
\hline F1 & $0.14 \pm 0.012$ & $42^{\circ} \pm 0.1$ & Pass & +++ \\
F2 & $0.13 \pm 0.022$ & $39^{\circ} \pm 0.3$ & Pass & ++++ \\
F3 & $0.12 \pm 0.013$ & $33.3^{\circ} \pm 0.2$ & Pass & ++ \\
F4 & $0.11 \pm 0.011$ & $28.7^{\circ} \pm 0.5$ & Pass & + \\
F5 & $0.15 \pm 0.023$ & $38.6^{\circ} \pm 0.1$ Pass & +++ \\
F6 & $0.14 \pm 0.030$ & $32.8^{\circ} \pm 0.4$ Pass & ++++ \\
F7 & $0.13 \pm 0.023$ & $28.3^{\circ} \pm 0.3$ Pass & ++ \\
F8 & $0.12 \pm 0.013$ & $25.7^{\circ} \pm 0.3$ Pass & + \\
\hline
\end{tabular}

All the values are in mean \pm SD $(n=3) . * *$ Where: + : Gel slowly, remain for $5 \mathrm{~min}$, ++ : Immediate gelation, remain for several minutes, +++: Immediate gelation but for few extended periods, ++++: Immediate gelation, harder gel but for more extended periods. SD: Standard deviation as the shear rate increased, the viscosity of gel decreased indicating shear thinning pseudoplastic flow property [32]

At $\mathrm{pH}$ of the preparation listed previously in Table 2, the formulations were in a liquid state and exhibited low viscosity. An increase in the $\mathrm{pH}$ to 6.8 caused the solutions to transform into gels with high viscosity

The viscosity of the formulations was found to be influenced by the concentration of polymers used; hence, a significant increase $(\mathrm{p}<0.05)$ in viscosity was observed with increasing polymer concentrations. This may be due to higher degree of cross-linking at higher concentrations of polymers [33].

Using different polymer grades resulted in a significant increase in viscosity $(\mathrm{p}<0.05)$. Formulations containing carbopol 940 (F5-F8) exhibited higher viscosity than formulations containing carbopol 934 (F1-F4) at the same concentration. Different rheological properties and viscosity values between the two grades are mainly reflected by the polymer particle size, molecular weight between cross-links, allocation of molecular crosslinks, and the fraction of the overall units that arise as terminal units, i.e., free chain ends [34]

\section{In vitro release study}

Graphical representations of release profile for in situ gels regarding the effect of polymer concentration are shown in Figs. 3 and 4 using carbopol 934 and 940, respectively.

The results indicated that, as the concentration of carbopol increases, the release of drug decreases. F4 and F8 with 0.7\% carbopol 934 and 940 have slowest release profile. The results of $t_{80} \%$ (time required for $80 \%$ of drug to be released) are shown in Table 4 .

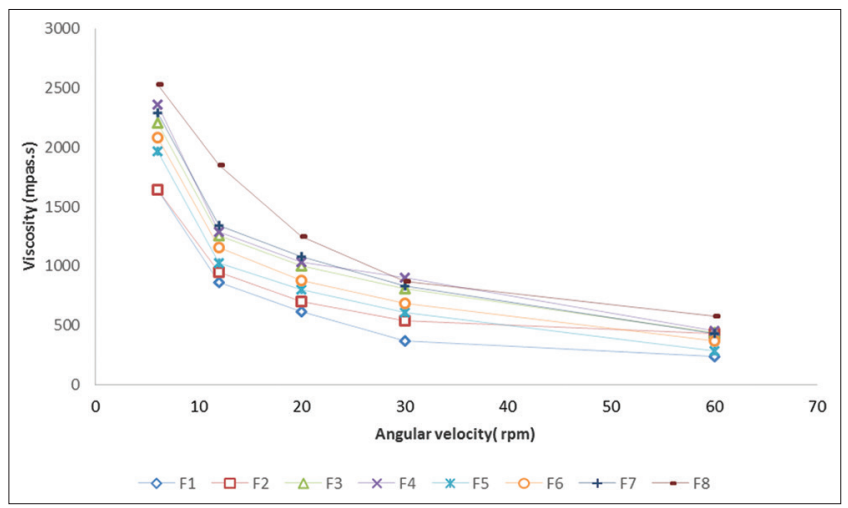

Fig. 1: The viscosity of in situ gel at non-physiological pH (before gelation), (mean \pm standard deviation, $n=3$ )

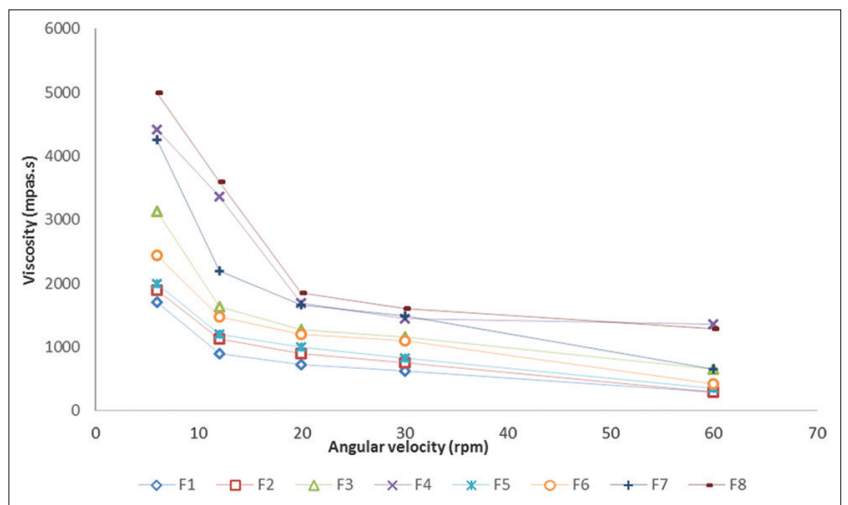

Fig. 2: The viscosity of in situ gel at physiological pH (after gelation), (mean \pm standard deviation, $\mathrm{n}=3$ ) 
A significant increase in $t_{80} \%$ was observed as the concentration of polymer increases.

The above results can be explained by rheological studies where the rate of drug release decreases as the viscosity of the in situ gel increases due to the presence of higher concentration of polymer, resulting in this retardation effect $[35,36]$

Figs. 5 and 6 show the effect of polymer grade on the dissolution profile. It seems that in situ gels formulated with carbopol 940 have longer dissolution profile in comparison with carbopol 934-based in situ gels at the same concentration.

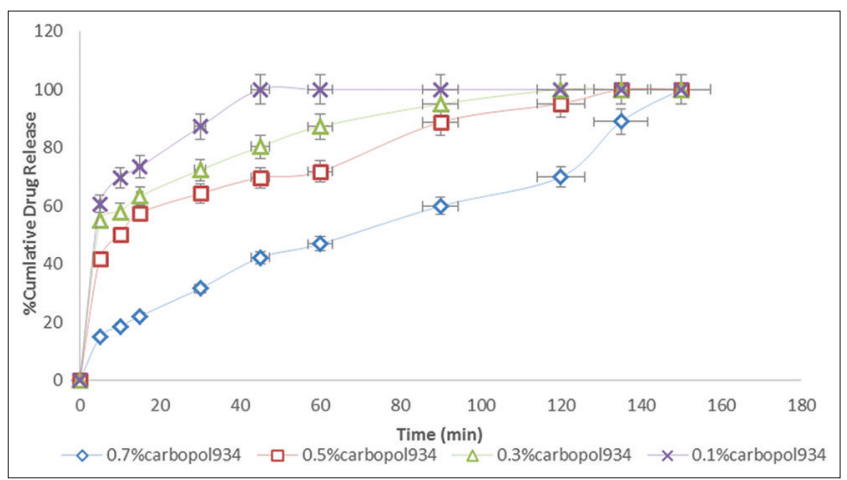

Fig. 3: Effect of carbopol 934 concentration on the release profile of $\mathrm{F} 1, \mathrm{~F} 2, \mathrm{~F} 3$, and $\mathrm{F} 4$ in phosphate buffer $\mathrm{pH} 6.8$ at $37^{\circ} \mathrm{C}$, (mean \pm standard deviation, $\mathrm{n}=3$ )

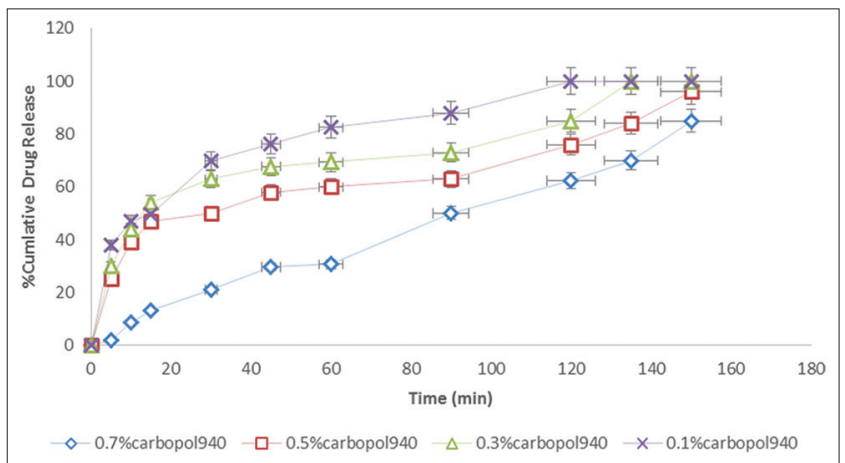

Fig. 4: Effect of carbopol 940 concentration on the release profile of $\mathrm{F5}, \mathrm{F} 6, \mathrm{~F} 7$, and $\mathrm{F} 8$ in phosphate buffer $\mathrm{pH} 6.8$ at $37^{\circ} \mathrm{C}$, (mean \pm standard deviation, $\mathrm{n}=3$ )

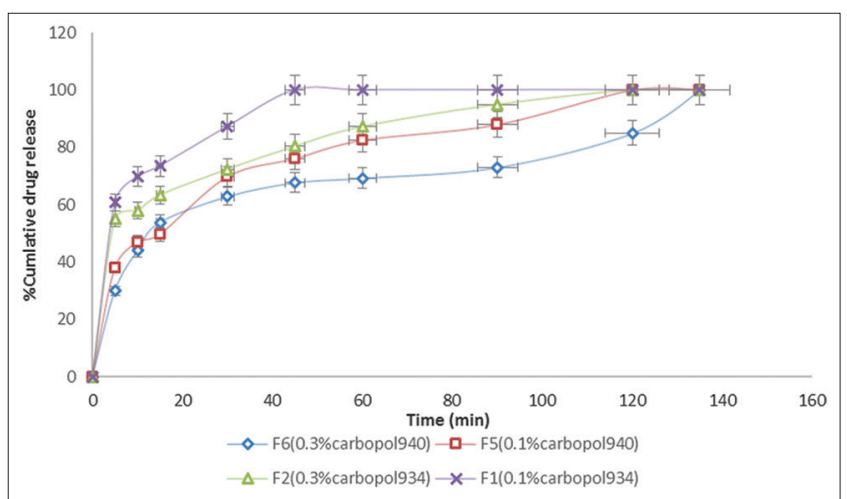

Fig. 5: Effect of polymer grade on the release profile of F1, F5 $\mathrm{F} 2$, and $\mathrm{F} 6$ in phosphate buffer $\mathrm{pH} 6.8$ at $37^{\circ} \mathrm{C}$, (mean \pm standard deviation, $n=3$ )
This is also consistent with the rheological study as shown in Fig. 2, in which formulas F5, F6, F7, and F8 based on carbopol 940 have higher viscosity compared to F1, F2, F3, and F4 based on carbopol 934

In vitro release of drug from formulation and gelation studies indicates that F2 containing $0.3 \%$ carbopol 934 and xanthan gum $0.2 \%$ was considered as an optimized formulation, in which $80 \%$ of drug is released within $45 \mathrm{~min}$ and might provide an effective painless anesthetic effect during dental treatment.

\section{Dissolution profile comparison}

The in vitro similarity factor $f 2$ was assessed to compare the dissolution profile of the prepared formulations to investigate the effect of increasing polymer concentration as well as the effect of using different carbopol grades on the release properties.

The results of dissolution profile comparison indicated that the dissolution profile of $\mathrm{F} 1$ is different from F2, F3, and F4 profiles. F5 does not resemble F6, F7, and F8 as well as F7 and F8 have non-equivalent profiles as shown in Table 5 . This indicates that

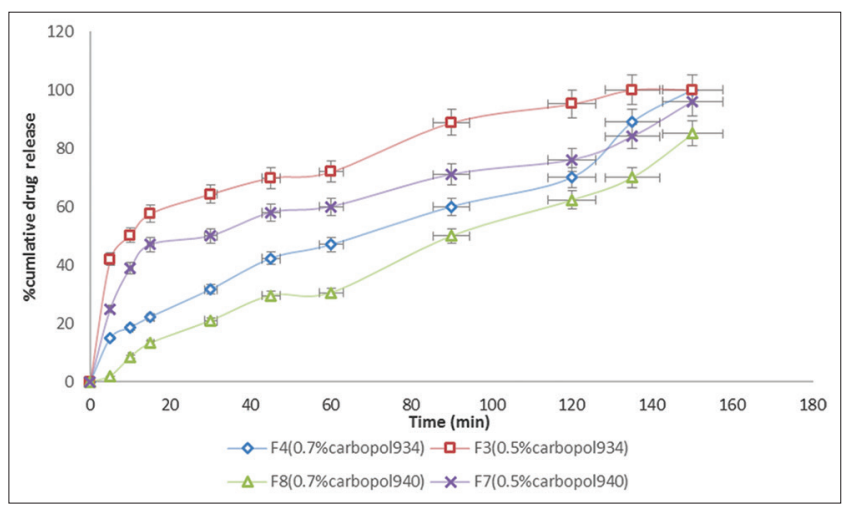

Fig. 6: Effect of polymer grade on the release profile of F3, F7, $\mathrm{F4}$, and $\mathrm{F} 8$ in phosphate buffer $\mathrm{pH} 6.8$ at $37^{\circ} \mathrm{C}$, (mean \pm standard deviation, $\mathbf{n}=3$

Table 4: $\mathrm{t}_{80} \%$ values

\begin{tabular}{ll}
\hline Formulation code $-\mathbf{t}_{\mathbf{8 0}} \mathbf{\%}$ (min) & \\
\hline F1 & $23 \pm 2.3$ \\
F2 & $45 \pm 1.2$ \\
F3 & $74 \pm 1.4$ \\
F4 & $128 \pm 1.5$ \\
F5 & $55 \pm 2.4$ \\
F6 & $107 \pm 1.9$ \\
F7 & $127 \pm 2.4$ \\
F8 & $145 \pm 1.7$ \\
\hline
\end{tabular}

$t_{80} \%$ is the time required for $80 \%$ of drug to be released. All the values are in mean \pm SD, $(n=3)$. SD: Standard deviation

Table 5: Values of similarity factor $f_{2}$ for the release profile in phosphate buffer pH 6.8

\begin{tabular}{llllllll}
\hline Formulation\# & F2 & F3 & F4 & F5 & F6 & F7 & F8 \\
\hline F1 & 47.5 & 37 & 15.3 & 31.8 & & - & - \\
F2 & - & 51.2 & - & - & 40.8 & - & - \\
F3 & - & - & 26.1 & - & - & 44.3 & - \\
F4 & - & - & - & - & - & - & 46.9 \\
F5 & - & - & - & - & 40.3 & 40.8 & 54.6 \\
F6 & - & - & - & - & - & 54.6 & -18.1 \\
F7 & - & - & & - & - & - & 29.5 \\
\hline
\end{tabular}

The use of different polymer grade, carbopol 934 and carbopol 940, resulted in non-equivalent dissolution profile at the same concentration where $f_{2}$ value is $<50$ 
increasing polymer concentration resulted in different dissolution profiles.

F2 and F3 as well as F6 and F7 are likely to possess similar dissolution characteristics since $f_{2}$ is between 50 and 100 , and this means that increasing the concentration for these batches does not have a considerable effect on dissolution profile [37].

The use of different polymer grade, carbopol 934 and carbopol 940, resulted in non-equivalent dissolution profile at the same concentration where $f_{2}$ value is $<50$.

F1 (0.1\% carbopol 934) has different dissolution profiles from F5 $(0.1 \%$ carbopol 940), F2 (0.3\% carbopol 934) is different from F6 ( $0.3 \%$ carbopol 940), F3 (0.5\% carbopol 934) is different from F7 (0.5\% carbopol 940), and F4 (0.7\% carbopol 934) is different from F8 (0.7\% carbopol 940).

This suggested that using different polymer grade resulted in considerable effect on the dissolution profile.

\section{Analysis of release mechanism}

The highest correlation coefficient $\left(\mathrm{R}^{2}\right)$ was obtained with KorsmeyerPeppas model for all formulations but combined with zero order in case of F8 which indicates that the drug release is ruled by both diffusions of the drug and dissolution/erosion of the gel matrix [38].

The release exponent (n) for all the formulations was in the range of $0.17-0.82$ as shown in Table 6. If $\mathrm{n}$ value has the limiting values of 0.45 or less, the release mechanism follows Fickian diffusion and higher values of $0.45-0.89$ for mass transfer follow a non-Fickian model or anomalous mechanism of drug release.

The drug release follows zero-order drug release and Case II transport if the $n$ value is 0.89 . For the values of $n$ higher than 0.89 , the mechanism of drug release is regarded as super Case II transport (relaxation) [39].

The drug diffusion through most types of polymeric systems is often best described by Fickian diffusion, but there might be also a relaxation of the polymer chains, which influences the drug release mechanism. This process is described as non-Fickian or anomalous diffusion. The observed deviation from Fickian mechanism, represented by F4 and F8, can be attributed to the reason that the formulations during gelation usually imbibe a large amount of dissolution fluid leading to a swollen state of the gel. This might have resulted in the polymeric chain relaxation, resulting in non-Fickian mechanism [40].

Table 6: Release kinetic data and correlation coefficients

\begin{tabular}{|c|c|c|c|c|c|c|c|c|c|}
\hline \multirow[t]{2}{*}{$\begin{array}{l}\text { Formula } \\
\text { code }\end{array}$} & \multicolumn{2}{|c|}{$\begin{array}{l}\text { Zero } \\
\text { order }\end{array}$} & \multicolumn{2}{|c|}{$\begin{array}{l}\text { First } \\
\text { order }\end{array}$} & \multicolumn{2}{|c|}{$\begin{array}{l}\text { Higuchi } \\
\text { Model }\end{array}$} & \multicolumn{3}{|c|}{$\begin{array}{l}\text { Korsmeyer- } \\
\text { Peppas model }\end{array}$} \\
\hline & $\mathbf{K}_{0}$ & $\mathbf{R}^{2}$ & $\mathrm{~K}_{1}$ & $\mathbf{R}^{2}$ & $\mathbf{K}_{\mathbf{H}}$ & $\mathbf{R}^{2}$ & kKp & $\mathbf{R}^{2}$ & $\mathbf{N}$ \\
\hline 1 & & & & & & & & 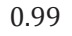 & \\
\hline 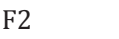 & & -0 & & & & & .2 & 99 & \\
\hline F3 & & -0.6 & & 0.66 & 10.6 & 0.76 & 9.4 & 99 & .24 \\
\hline & & & & & & & & & \\
\hline F5 & & 0. & & 0.89 & & 0 & & 9 & 0.34 \\
\hline F6 & 0.00 & 0.08 & & 0.77 & 8.9 & 0.82 & 24.7 & 0.97 & 0.25 \\
\hline F7 & 0.72 & 0.34 & 0.02 & 0.7 & 7.8 & 0.86 & 19.2 & 0.98 & 0.29 \\
\hline F8 & 0.55 & 0.99 & 0.01 & 0.97 & 5.5 & 0.89 & 1.2 & 0.99 & 0.82 \\
\hline
\end{tabular}

$\mathrm{K}_{0}, \mathrm{~K}_{1}, \mathrm{KH}$, and kKp are the release constants for zero, first, Higuchi, and Korsmeyer-Peppas model, $\mathrm{n}$ is the release index for Korsmeyer-Peppas

\section{CONCLUSION}

Lidocaine $\mathrm{HCl}$ was successfully formulated in a pH-triggered in situ gelling system using carbopol 934 in combination with xanthan gum. Applying of the in situ gel using spray tool regarded as a newer approach to improve easy dental application.
The developed formulation (F2) shows satisfactory results for gelling capacity, $\mathrm{pH}$, syringeability, release profile, and other physical properties.

It had been shown that increasing polymer concentration for both carbopol grades resulted in different dissolution profile when similarity factor $f_{2}$ is applied. Furthermore, different dissolution profiles were obtained using the same concentration but different polymer grades.

The in situ gelling system delivered as a spray will most probably get good acceptance by patients and health-care professionals because it is easy to apply and gradually erodes by dissolution of the gel also avoiding the need for removal. It can be concluded that lidocaine $\mathrm{HCl}$ in situ gel spray is a viable alternative to conventional oral gel as well as avoidance of needle usage.

\section{ACKNOWLEDGMENT}

We would like to thank College of Pharmacy/University of Baghdad, Department of Pharmaceutics, for providing access to the laboratory instruments, technical support, and continuous encouragement.

\section{CONTRIBUTION OF AUTHORS}

Halah Talal Sulaiman and Saba Abdulhadi Jabir conceived, designed the study, and collected the data, Khalid Kadhem Al-Kinanianalyzed thedata and revised the manuscript, and Halah Talal Sulaiman wrote the manuscript, revised, and approved the manuscript for publication.

\section{CONFLICTS OF INTEREST}

No conflicts of interest are associated with this work.

\section{REFERENCES}

1. Peppas NA, Langer R. New challenges in biomaterials. Science 1994;263:1715-20

2. Suisha F, Kawasaki N, Miyazaki S, Shirakawa M, Yamatoya K, Sasaki M, et al. Xyloglucan gels as sustained release vehicles for the intraperitoneal administration of mitomycin C. Int J Pharm 1998;172:27-32.

3. Miyazaki S, Endo K, Kawasaki N, Kubo W, Watanabe H, Attwood D, et al. Oral sustained delivery of paracetamol from in situ gelling xyloglucan formulations. Drug Dev Ind Pharm 2003;29:113-9.

4. Tushar N, Nayan G, Bhushan R, Sunil B, Pawar SP. In situ gel: Novel approach in sustained and controlled drug delivery system. Int J Pharm Sci 2013;4:1-18

5. Jones MR, Philip B. Massersmith BP. In-situ forming biomaterials, oral maxillofacial surgery. Clin North Am 2002;14:29-38

6. Qiu Y, Park K. Environment-sensitive hydrogels for drug delivery. Adv Drug Deliv Rev 2001;53:321-39.

7. Soppimath KS, Aminabhavi TM, Dave AM, Kumbar SG, Rudzinski WE. Stimulus-responsive: "Smart" hydrogels as novel drug delivery systems. Drug Dev Ind Pharm 2002;28:957-74.

8. Sonawan M, Shinkar D, Saudagar R. Mucoadhesive buccal drug delivery system: Review article. Int J Curr Pharm Res 2017;9:1-4

9. Thosar MM. Intra oral sprays-an overview. Int J Pharm Life Sci 2011;2:1235-46

10. Lee HS. Recent advanced in topical anesthesia. J Dent Anesth Pain Med 2016;16:237-44

11. Meechan JG. Effective topical anesthetic agent and techniques. Dent Clin N Am 2002;46:759-66.

12. Estafan DJ. Invasive and noninvasive dental analgesia techniques. Gen Dent 1998;46:600-3.

13. Ogle OE, Mahjoubi G. Local anesthesia: Agents, techniques, and complications. Dent Clin North Am 2012;56:133-48, 9

14. Hu L, Silva SM, Damaj BB, Martin R, Michniak-Kohn BB. Transdermal and transbuccal drug delivery systems: Enhancement using iontophoretic and chemical approaches. Int J Pharm 2011;421:53-62.

15. Ghosh S, Roy G, Mukherjee B. Dental mold: A novel formulation to treat common dental disorders. AAPS Pharm Sci Tech 2009;10:692-702.

16. Pagar SA, Shinkar DM, Saudagar RB, Development and evaluation of in situ nasal mucoadhesive gel of metoprolol succinate by using $3^{2}$ full factorial design. Int J Pharm Pharm Sci 2014;6:218-23.

17. Pandit AP, Pol VV, Kulkarni VS. Xyloglucan based in situ gel of 
lidocaine $\mathrm{HCl}$ for the treatment of periodontists. J Pharm 2016;2016:1-9.

18. Moffat AC, Osselton MD, Widdop B, Galichet LY. Clarke's Analysis of Drugs and Poisons. $4^{\text {th }}$ ed. London: Pharmaceutical Press; 2011. p. 1573.

19. Harish NM, Prabhu P, Charyulu RN, Gulzar MA, Subrahmanyam EV. Formulation and evaluation of in situ gels containing clotrimazole for oral candidiasis. Indian J Pharm Sci 2009;71:421-7.

20. Joshi M, Bolmal U, Dandagi P. Formulation and evaluation of cefuroxime axetil sol gel for periodontits. Int J Pharm Pharm Sci 2014;6:498-503.

21. Guhel MC, Nagori SA. Fabrication of modified transport fluconazole

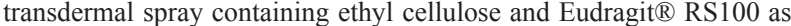
film formers. AAPS Pharm Sci Tech 2009;10:684-91.

22. Gupta C, Juyal V, Nagaich U. Formulation and optimization of a thermosensetive in situ gel of moxifloxacine hydrochloride for ocular drug delivery. Int J App Pharm 2018;10:123-30.

23. Murtaza G. Development of glutaraldehyde cross-linked metronidazole loaded chitosan microcapsules: Analysis of dissolution data using DDSolver. Latin Am J Pharm 2011;30:301-8.

24. Shahzad MK, Ubaid M, Raza M, Murtaza G. The formulation of flurbiprofen loaded microspheres using hydroxyl propyl methyl cellulose and ethyl cellulose. Adv Clin Exp Med 2013;22:177-83.

25. Costa P, Sousalobo JM. Modeling and comparison of dissolution profiles. Eur J Pharm Sci 2001;13:123-33.

26. Patil S, Kadam A, Bandgar S, Patil S. Formulation and evaluation of an in situ gel for ocular drug delivery of anticonjunctival drug. Cellul Chem Tech 2015;49:35-40.

27. Troy DV, Hauber MJ, Brien MA. Remington, the Science and Practice of Pharmacy. $21^{\text {st }}$ ed. Philadelphia, PA, USA: Lippincott Williams and Wilkins; 2006. p. 771.

28. Katzbauer B. Properties and applications of xanthan gum. Polym Degrad Stab 1998;59:81-4.

29. Deshpande JM, Shah PB. Formulation and development $\mathrm{pH}$ induced in-situ gelling system of an anti-infective drug for sustained ocular drug delivery. J Pharm Sci Biosci Res 2012;2:238-44.

30. Nandgude T, Thube R, Jaiswal N, Deshmukh P, Chapta V, Hire N. Formulation and evaluation of $\mathrm{pH}$ induced in situ gel of salbutamol sulphate. Int J Pharm Sci Nanotech 2008;1:177-83.

31. Phaechamud T, Charoenteeraboon J, Saengthongpinit W, Chuekaew A. Spray pattern of oral cavity sprays containing the herbal extracts. Res J Pharm Bio Chem Sci 2012;3:1301-6.

32. Bisht NN, Goswami L, Kothiyal P. Preparation and evaluation of in situ topical oral gel of levofloxacine by using combination of polymer. Ind J Drug 2014;2:142-51.

33. Aslani A, Ghannadi A, Najafi H. Design, formulation and evaluation of a mucoadhesive gel from Quercus brantii L. And Coriandrum sativum L. As periodontal drug delivery. Adv Biomed Res 2013;2:21.

34. Kumara P, Prakash SC, Lokesh P, Manral KK. Viscoelastic properties and rheological characterization of carbomer. Int J Latest Res Eng Tech 2015;1:17-30.

35. Das S, Samantha A, Bose A. Design, development and evaluation of fluconazole topical gel. Asian J Pharm Clin Res 2015;8:132-5.

36. Kumar AS, Gupta VN, Guda DV, Sivadasu P. Formulation and development of in situ forming gel for the treatment of oral thrush. Asian J Pharm Clin Res 2018;11:342-6.

37. Kipo SL, Oppong EE, Kwakye KO. Physicochemical evaluation and tablet formulation properties of shea tree gum. Asian J Pharm Sci 2014; $7: 121-7$

38. Salih OS, Nief RA. Effect of natural and synthetic polymer on the properties of candesartan cillexetil matrix tablet prepared by dry granulation. Asian J Pharm Clin Res 2016;9:161-70.

39. Dash S, Murthy PN, Nath L, Chowdhury P. Kinetic modeling on drug release from controlled drug delivery systems -review. Acta Poloniae Pharm Drug Res 2010;67:217-23.

40. Nagarwal RC, Srinatha A, Pandit JK. In situ forming formulation: Development, evaluation, and optimization using $3^{3}$ factorial design. AAPS Pharm Sci Tech 2009;10:977-84. 